\title{
CYSTIC FIBROSIS OF THE PANCREAS
}

\author{
BY \\ W. DOUGLAS HENDERSON, M.B., F.R.C.P.ED. \\ Hon. Physician, Woking Victoria Hospital
}

Passini (1919) was apparently the first to describe a case of faulty digestion in an infant due to pancreatic disease, and it would appear from a brief survey of the literature that not many cases of cystic fibrosis of the pancreas have been reported in this country, whereas in the United States, since Andersen (1938) correlated the pancreatic changes with steatorrhoea and pneumonia to form the syndrome of cystic fibrosis, many more cases have been reported. Menten and Middleton (1944) suggest that there is a significant increase in this disease.

Wolman (1942), in an excellent review of the literature, points to the importance of differential diagnosis from coeliac disease, and this case is reported to show some of the difficulties of diagnosis before death.

\section{Case history}

M. K., a male child aged twenty-two months, was admitted to the Woking Victoria Hospital on April 4, 1945, giving a history of not gaining weight and passing frequent large and offensive stools. At birth he weighed $7 \mathrm{lb} .13 \mathrm{oz}$. and was breast fed for five weeks. He always appeared hungry and the feed was changed to a dried milk. He then gained normally until he was one year old, when he weighed $21 \mathrm{lb}$. He had had a big abdomen and an abnormal appetite from birth. There were no previous illnesses and it was particularly determined that the child had never had a cough. He could not tolerate war-time concentrated orange juice and cod-liver oil was not well taken. At fifteen months diarrhoea started with large, oily stools, seven to eight a day.

The mother is apparently healthy and no relevant medical history could be obtained. The father is stated to have been a premature baby, was jaundiced at birth and did not walk till he was three years old, having worn calipers until then. There is one other child, a girl aged nine months, who is apparently perfectly healthy.

On admission the child weighed $24 \mathrm{lb}$. and was definitely under-nourished, with a protruberant abdomen. Muscle wasting was not prominent. Clinical examination showed all organs apparently healthy, but the stools, which were large, pale, offensive and of a soft, greasy consistency, were passed up to seven or eight times a day. The Vollmer tuberculin patch test was negative.

In spite of the appetite, which was enormous (the child was crying for food all day) a provisional diagnosis of coeliac disease was made and appeared to be borne out by a fat estimation of the stool. This, on April 5, showed that, of the dried faeces:-
Total fat . 65.8 per cent.

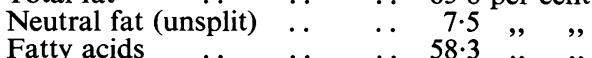
(of the faecal fat, 88.6 per cent. was split).

There was still a doubt as to the true nature of the disease and it was decided to carry out vitamin A absorbtion tests and glucose tolerance tests. Before these could be done the child developed measles and on April 18 the weight had dropped to $22 \mathrm{lb}$. $7 \mathrm{oz}$; it was therefore decided to begin treatment at once with liver extract and vitamin B complex, as recommended by Paterson et al. (1945). The preparation used was Heparglandol (Roche) and seven injections on alternate days were given intramuscularly.

On April 27 a further fat estimation of the stool showed a fall in the fat content, the figures being:-

$$
\begin{aligned}
& \begin{array}{lllll}
\text { Total fat } \quad . & \ldots & \ldots & 34.5 & \text { per cent. }
\end{array}
\end{aligned}
$$

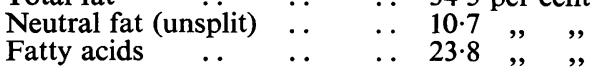

$$
\begin{aligned}
& \text { (of the faecal fat, } 69 \text { per cent. was split). }
\end{aligned}
$$

At this stage the child developed bronchopneumonia and became seriously ill. Treatment with Heparglandol was stopped and chemotherapy was commenced. It was noted that sulphamezathene and sulphathiazole had no effect upon the course of the pneumonia, whilst sulphadiazine had a slight effect only. A course of penicillin, 15,000 units three-hourly, was then tried, but had no effect on the lung condition, and death took place on May 29.

A third fat estimation had been done on May 19 and there was again an increase:-

$$
\begin{aligned}
& \begin{array}{lllll}
\text { Total fat } & \text {. } & \text {. } & \text {. } & 56 \cdot 1 \text { per cent. }
\end{array} \\
& \begin{array}{lllll}
\text { Neutral fat (unsplit) } & \ldots & \ldots & 10.4 & \text {, , }
\end{array}
\end{aligned}
$$

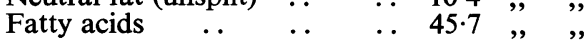

$$
\begin{aligned}
& \text { (of the faecal fat, 81.4 per cent. was split). }
\end{aligned}
$$

Post-mortem report. The body was that of a thin, emaciated child, with a distended abdomen. The liver was found to be slightly enlarged and showed a pale cut surface. The stomach and intestines were normal, but the mesenteric glands were large. The pancreas was long and thin and pink in colour. It was adherent to surrounding structures and felt hard and nodular. The lungs showed areas of collapse and consolidation and a thin mucopus could be expressed from the bronchioles. All other organs were healthy. 


\section{Histological report}

Pancreas. Cystic fibrosis. No evidence of acute or chronic inflammation. Fibrous tissue was greatly in excess with swollen acini scattered throughout. The acini were filled with a pink eosin staining substance (fig. 1).

LIVER. Acute venous passive congestion.

MESENTERIC GLANDS. Chronic lymphadenitis.

\section{Discussion}

Blackfan and May (1938) state that the clinical manifestations of cystic fibrosis of the pancreas are limited in variety, but are so common to many disorders of infancy that it has not been found possible to determine accurately the dependable diagnostic features. On the other hand, Kennedy and Baggenstoss (1943) give the following features, which go to make the diagnosis of cystic fibrosis: the combination of steatorrhoea, chronic cough and absence of trypsin.

It is regretted that in this case there had been no estimation of trypsin, but even so the difficulties of diagnosis are borne out. It is here shown that estimations of the fat content of the stool cannot establish the diagnosis, as the figures show what would appear to be a typical case of coeliac disease.

Theoretically, an absence of pancreatic lipase will lead to an increase in neutral unsplit fats in the stool, but this has not been borne out in practice, as in this case, in which there was a constantly high percentage of split fats, and all the while the child was under observation it had been fed on a normal diet.

Deem and McGeorge (1941) point out that the concentration of fat in the stool depends on the diet and it has been suggested that where there is a high percentage of fatty acids, the fats in the diet have been split, presumably by lipase of the intestinal juice.

In spite of the absence of definite evidence of pancreatic activity in this case, it is difficult to assume that the fat from a normal diet could have been acted upon by lipase from the intestinal juice alone, to such an extent as to give so high a percentage of split fats, and it must be assumed that a good deal of the remaining acinar tissue of the pancreas must have been in an active state and that there was free exit from the gland to the intestine so that the ferment could digest the fats. Thus it must be reasonable to assume that there is a normal or increased secretion of fat digestants from the pancreas.

Menten and Middleton (1944) report eighteen cases with diffuse definite dilatation of pancreatic acini and associated pneumonia. They state that radiological examination of the lungs in their cases showed remarkable similarity in the unusual enlargement of hilar shadows and a bilateral shadow decreasing to the periphery and suggest this as a diagnostic feature.

Snelling and Erb (1942) had also found that physical signs of lung involvement such as bronchitis, collapse and consolidation of the lung, broncho-pneumonia and bronchiectasis were present on admission or during the period of observation in all their nineteen cases.

No evidence of lung involvement could be found in the present case to support these contentions, apart from some enlargement of the hilar shadow; this latter was not really excessive, although radiological examination of the chest was not done until May 14, after the pneumonia had developed.

Points in the diagnosis of cystic fibrosis are: (i) early age of onset; (ii) steatorrhoea associated with a large appetite; and (iii) ? absence of pancreatic enzymes obtained by duodenal intubation. Treatment with vitamin $\mathbf{A}$ and pancreatin has been tried in many cases, but the results have been too indefinite to be of value and at present treatment of

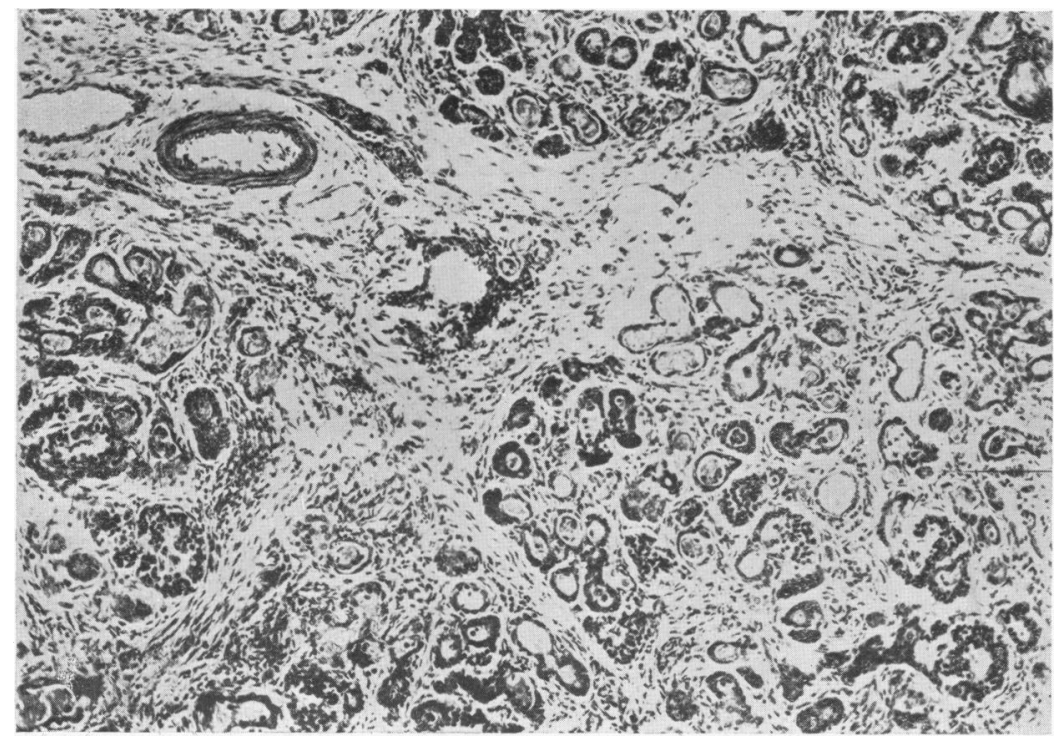

FIG. 1.-Section of pancreas showing cystic acini and excess of fibrous tissue. (Haem. and Eosin.) 
the disease can only be considered as hopeless. It might be worth while to consider treatment with liver extract and vitamin B, as it was noted that there was a drop in the fat content of the stool after seven injections of Heparglandol.

Thanks are due to Dr. D. C. L. Derry and Dr. Griffiths of Botley's Park E. M. S. Hospital, for their reports on the pathological specimens and fat estimations respectively.

\section{REFERENCES}

Andersen, D. H. (1938). Amer. J. Dis. Child., 56, 34.
Blackfan, K. D., and May, C. D. (1938). J. Pediat., 13, 627.

Deem, H., and McGeorge, M. (1941). N. Z. med. J., 40, 155 .

Kennedy, R. L. J., and Baggenstoss, A. H. (1943). Proc. Mayo Clin., 18, 487.

Menten, M. L., and Middleton, T. O. (1944). Amer. J. Dis. Child., 67, 355.

Passini, F. (1919). Dtsch. med. Wschr., 45, 851.

Paterson, D., Pierce, M., and Peck, E. (1945). Arch. Dis. Childh., 19, 99.

Snelling, C. E., and Erb, I. H. (1942). Ibid., 17, 220

Wolman, I. J. (1942). Amer. J. med. Sci., 203, 900. 